\title{
2018 Korean Clinical Imaging Guideline for Hemoptysis
}

\author{
Mi-Jin Kang, $M D^{1}$, Jin Hwan Kim, MD, PhD ${ }^{2}$, Yoon Kyung Kim, MD, PhD ${ }^{3}$, Hyun Joo Lee, $M D^{4}$, \\ Kyung Min Shin, $\mathrm{MD}^{5}$, Jung Im Kim, MD, PhD ${ }^{6}$, Hyun Ju Lee, MD, PhD' , Kyung Hyun Do, MD, PhD', \\ Hwan Seok Yong, MD, PhD ${ }^{8}$, Sol Ji Choi, $\mathrm{PhD}^{9}$, Miyoung Choi, RN, MPH, PhD ${ }^{9}$, Jung Im Jung, MD, $\mathrm{PhD}^{10}$ \\ ${ }^{1}$ Department of Radiolgoy, InJe University Sanggye Paik Hospital, Seoul 01757, Korea; ${ }^{2}$ Department of Radiology, Chungnam National University \\ Hospital, Chungnam National University School of Medicine, Daejeon 35015, Korea; ${ }^{3}$ Department of Radiology, Gachon University Gil Hospital, \\ Incheon 21565, Korea; ${ }^{4}$ Department of Radiology and Research Institute of Radiology, University of Ulsan College of Medicine, Asan Medical \\ Center, Seoul 05505, Korea; ${ }^{5}$ Department of Radiology, Kyungpook National University Medical Center, Daegu 41944, Korea; ${ }^{6}$ Department of \\ Radiology, Kyung Hee University Hospital at Gangdong, Kyung Hee University College of Medicine, Seoul 05278, Korea; ${ }^{7}$ Department of Radiology, \\ Seoul National University Hospital, Seoul 03080, Korea; ${ }^{8}$ Department of Radiology, Korea University Guro Hospital, Korea University College of \\ Medicine, Seoul 08308, Korea; ${ }^{9}$ Division for Healthcare Technology Assessment Research, National Evidence-based Healthcare Collaborating \\ Agency, Seoul 04554, Korea; ${ }^{10}$ Department of Radiology, Seoul St. Mary's Hospital, College of Medicine, The Catholic University of Korea, Seoul \\ 06591, Korea
}

In 2014, the American College of Radiology (ACR) announced the guideline for the appropriate diagnostic approach and treatment of patients according to the severity of hemoptysis and risk for lung cancer. However, the application of the ACR guideline in Korea may not be appropriate, because many patients in Korea have active tuberculosis or pulmonary fibrosis due to previous tuberculosis. The Korean Society of Radiology and Korean Society of Thoracic Radiology have proposed a new guideline suitable for Korean practice. This new guideline was prepared through the consensus of a development committee, working party, and an advisory committee. The guideline proposal process was based on an evidence-based clinical imaging guideline proposed by the development committee. Clinical imaging guideline for adult patients with hemoptysis is as follows: Chest radiography is an initial imaging modality to evaluate hemoptysis. Contrast-enhanced chest CT is recommended in patients with two risk factors for lung cancer ( $>40$ years old and $>30$ pack-year smoking history), moderate hemoptysis (>30 mL/24 hours) or recurrent hemoptysis. Contrast-enhanced chest CT is also recommended in patients with massive hemoptysis ( $>400 \mathrm{~mL} / 24$ hours) without cardiopulmonary compromise.

Keywords: Guideline; Hemoptysis; Thorax; Lung; Radiography; X-ray; Computed tomography; Evidence; Republic of Korea

Received February 22, 2018; accepted after revision April 3, 2018.

This study was supported by the National Evidence-based Collaborating Agency (NECA-C-15-003) and the Korean Society of Radiology (NECA-S-15-002).

This Guideline has been published jointly by invitation and consent in both the Journal of the Korean Society of Radiology (in Korean) and the Korean Journal of Radiology (in English).

Corresponding author: Jung Im Jung, MD, PhD, Department of Radiology, Seoul St. Mary's Hospital, College of Medicine, The Catholic University of Korea, 222 Banpo-daero, Seocho-gu, Seoul 06591, Korea.

- Tel: (822) 2258-1435• Fax: (822) 599-6771•E-mail: jijung@catholic.ac.kr

This is an 0pen Access article distributed under the terms of the Creative Commons Attribution Non-Commercial License (https://

creativecommons.org/licenses/by-nc/4.0) which permits unrestricted non-commercial use, distribution, and reproduction in any medium, provided the original work is properly cited. 


\section{Background of the Development of the Korean Clinical Imaging Guideline}

Hemoptysis is the expectoration of blood to mouth or nose that originates from the respiratory tract. Clinical management is different according to the severity of hemoptysis based on the volume of blood loss. However, retained blood in lung parenchyma can be underestimated due to the difficulty in determining the exact volume of blood loss in routine practice. Diagnostic imaging is salient for appropriate diagnosis and treatment because hemoptysis can originate from various diseases such as acute benign disease (including bronchitis), chronic benign disease (including bronchiectasis), or malignant tumor.

A clinical imaging guideline for hemoptysis has been previously published by the American College of Radiology (ACR) (1). ACR guideline states diagnostic and treatment strategies according to the severity of hemoptysis and risk factor for lung cancer. The ACR emphasized the importance of undiagnosed lung cancer in hemoptysis patients.

However, there is a need for a guideline specific to Korea, because it is an endemic tuberculosis area with a high rate of hemoptysis patients with pulmonary fibrosis caused by previous tuberculosis or hemoptysis from active tuberculosis. Consequently, the development committee, working party, and an advisory committee have developed a guideline suitable for Korean practice.

\section{Adaptation Process of the Guidelines}

The guideline development process was based on a guideline adaptation methodology process suggested by the development committee (2).

\section{Key Questions}

The key questions made by working group were reviewed and revised by the development committee and consensus group. The consensus group represented the suggested end user and was selected from The Korean Academy of Tuberculosis and Respiratory Disease. The finalized key question is in a structured form below.

1. What is the most appropriate imaging test to diagnose the cause of hemoptysis in an adult patient with hemoptysis?

\section{Search Guidelines}

The development committee searched for guidelines using international databases (Ovid-MEDLINE and Ovid-

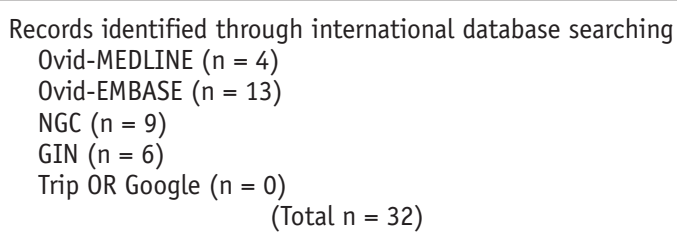

Records after duplication removed (domestic $n=15$ /international $n=32$ ) (Total $n=47$ )

$\operatorname{KGC}(n=9)$

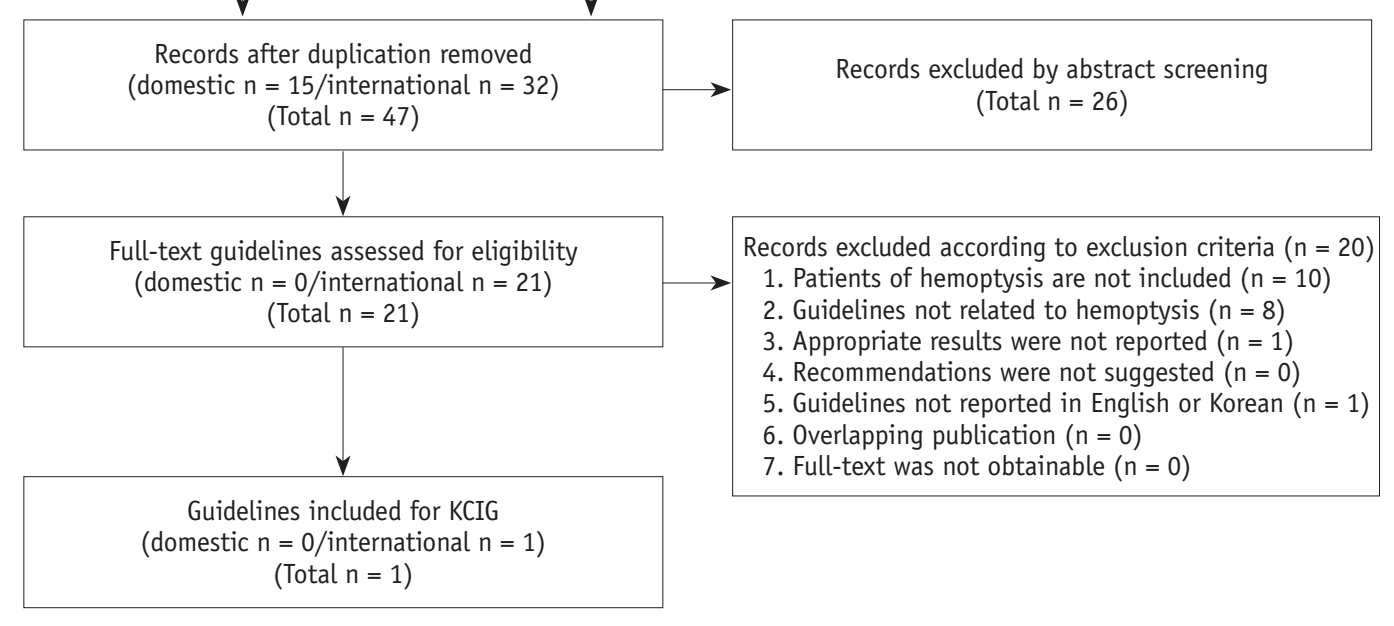

Records identified through domestic database searching KoreaMed $(n=4)$

$\operatorname{KMBASE}(n=1)$

KoMGI $(n=0)$

Searched guideline through manual method $(n=1)$

(Total $n=15$ )

Fig. 1. Flow chart for literature selection. $\mathrm{GIN}=$ Guideline International Network, $\mathrm{KCIG}=$ Korean Clinical Imaging Guidelines, $\mathrm{KGC}=\mathrm{Korean}$ Guideline Clearinghouse, KoMGI = Korean Medical Guidelines and Information, NGC = National Guideline Clearinghouse 
Table 1. AGREE II

\begin{tabular}{ccc}
\hline Source of Recommendation & AGREE II Score & Proposal of Developmental Committee \\
\hline ACR Appropriateness Criteria ${ }^{\circledR}$ hemoptysis & 66 & Recommended \\
\hline
\end{tabular}

Not recommended: AGREE score $<50$. ACR = American College of Radiology, AGREE II = Appraisal of Guidelines for Research \& Evaluation II

\section{Table 2. Criteria for Evidence Level of Each Evidence Literature}

\begin{tabular}{ll}
\hline Level & Content \\
\hline 1 & 2) Gearch satisfying all of criteria following three \\
2) Consecutive patients study \\
3) Blind interpretation \\
Systematic review of level 1 \\
Randomized controlled trial or cross-sectional cohort study that compares index test to comparators \\
Research satisfying all of criteria following two \\
1) Good reference standard \\
2) Consecutive patients study or blind interpretation \\
Systematic review of level 2 \\
Observational studies that compares index test to comparators \\
Without consistently applied reference standards \\
Case-control study \\
Poor or non-independent reference standard
\end{tabular}

Adapted from Choi et al. Korean J Radiol 2017;18:208-216 (2)

Table 3. Grades of Korean Clinical Imaging Guideline Recommendation

\begin{tabular}{ccc}
\hline Grading & \multicolumn{1}{c}{ Content } & Meaning \\
\hline A & Recommended & $\begin{array}{c}\text { This intervention (examination) has enough evidence to support desired effect, and therefore, is } \\
\text { recommended }\end{array}$ \\
B $\quad \begin{array}{c}\text { (Conditional) } \\
\text { recommended }\end{array}$ & $\begin{array}{c}\text { This intervention (examination) has intermediate to enough level of evidence to support desired effect } \\
\text { Provide intervention (examination) selectively, or for specific individuals based on expert's judgment }\end{array}$ \\
C N not recommended & $\begin{array}{c}\text { This intervention (examination) has enough evidence to support non-desired effect, and therefore, is not } \\
\text { recommended (use of this examination is not recommended) }\end{array}$ \\
& $\begin{array}{c}\text { This intervention (examination) does not have enough evidence to either support or reject effectiveness, } \\
\text { and needs further research } \\
\text { This intervention (examination) has very low level of certainty for desired effect, and decision based on } \\
\text { recommendation grading has no meaning }\end{array}$
\end{tabular}

Adapted from Choi et al. Korean J Radiol 2017;18:208-216 (2)

EMBASE), several international sites associated with guidelines (National Guideline Clearinghouse and Guideline International Network) and major domestic databases (KoreaMed, KMbase, Korean Medical Guidelines and Information, and Korean Guideline Clearinghouse).

In addition, the websites of major academic societies and institutions were also searched along with a manual database search. We performed literature searches from 2000 to July, 2015 for the keywords hemoptysis, computerized tomography, or bronchoscopy, using Medical Subject Heading (MeSH) terms or Embase subject headings (EMTREE). Guidelines or articles published after that period were included by an up-to-dated search.

\section{Selection of Searched Guidelines}

A total of 47 guidelines were searched: 32 guidelines in an international database, 14 guidelines in a domestic database, and 1 guideline by a manual search. In the primary screening process, 21 records were selected after reviewing the title and abstract of an identified study or guideline. One guideline was selected after the full-texts of identified literature were reviewed in the secondary screening process that also noted the reason for the exclusion of any specific literature selected (Fig 1). 


\section{Quality Appraisal of the Guidelines}

The final selected guidelines underwent quality appraisal using the Korean Appraisal of Guidelines for Research \& Evaluation II (AGREE II) tool of the development committee. Final appraisal results were provided to the working group (Table 1). The working group selected one guideline for the key question in consideration of the quality of the selected guideline.

\section{Grading the Level of Evidence and Drafting the}

Recommendation Document

Working group members reviewed evidence in the literature that supported the final selected guideline recommendations. Grading the level of evidence for each literature was performed to create an evidence table (Supplementary Table 1 in the online-only Data Supplement) according to the evidence level criteria of the Korean Clinical Imaging Guidelines (K-CIG) (Tables 2, 3). The draft version of the recommendation document was based on the prepared evidence table after a final discussion of the working group.

\section{Agreement of the Recommendation Grades}

The draft version of the recommendation document prepared by the working group was reviewed and discussed by the development committee. The final level of evidence and grade of recommendation was determined by the consensus of the development committee and working group, according to K-CIG criteria (2).

\section{Finalizing the Recommendation Document}

The Delphi method was used for formal consensus. The consensus group was composed of clinical imaging experts, end-users from the clinical imaging guideline-related academic societies (The Korean Academy of Tuberculosis and Respiratory Disease), and research methodology experts.

The results of the Delphi were as follows: degree of agreement on primary survey was 7.3-8.6 (standard deviation: $0.5-0.9$ ) and degree of agreement on secondary survey 6.9-8.5 (standard deviation: 0.5-0.8).

\section{External Review and Approval of Clinical Guideline}

Clinical experts related to the area of the recommendations, such as members from The Korean Academy of Tuberculosis and Respiratory Disease reviewed the final recommendations. Feedback and modification was subsequently reflected in the documents.

\section{Recommendations}

\section{Key Question}

1. What is the most appropriate imaging test to diagnose the cause of hemoptysis in an adult patient with hemoptysis?

\section{[Recommendation 1-1]}

Chest radiography is suggested for initial evaluation in all adult patients with hemoptysis.

(recommendation grade $\mathrm{A}$, evidence level II)

\section{[Recommendation 1-2]}

Contrast-enhanced chest CT scan is recommended to diagnose the cause of hemoptysis in all adult patients with hemoptysis and who have two risk factors for lung cancer (> 40 years old and $>30$ pack-year smoking history).

(recommendation grade $A$, evidence level II)

\section{[Recommendation 1-3]}

Contrast-enhanced chest CT scan is recommended to diagnose the cause of hemoptysis in all adult patients with moderate hemoptysis ( $>30 \mathrm{~mL} / 24$ hours) or recurrent hemoptysis.

(recommendation grade $A$, evidence level II)

\section{[Recommendation 1-4]}

Contrast-enhanced chest CT scan should also be considered in adult patients with massive hemoptysis (> $400 \mathrm{~mL} / 24$ hours) and preserved cardiopulmonary function.

(recommendation grade $\mathrm{A}$, evidence level III)

\section{Evidence Summary}

Hemoptysis is spitting blood from the respiratory tract due to various causes that range from blood tinged sputum to massive hemoptysis. Causes of hemoptysis include benign disease such as bronchiectasis, acute bronchitis, chronic bronchitis, tuberculosis, diffuse interstitial lung disease, and pulmonary venous malformation or malignant disease such as lung cancer and idiopathic. Therefore, appropriate screening test and complete medical examinations are required (3-5). This paper proposes a clinical imaging guideline for adult patients with hemoptysis.

The guideline recommends chest radiography as an initial evaluation for all adult hemoptysis patients. Chest radiography can help lateralize the bleeding site and screen for the presence or absence of abnormality in the pleura 
and lung parenchyma $(3,6,7)$.

Clinical imaging guidelines differ according to the amount of hemoptysis: minor ( $<30 \mathrm{~mL} / 24$ hours), moderate (30-400 $\mathrm{mL} / 24$ hours), or massive hemoptysis (> $400 \mathrm{~mL} / 24$ hours) (7-10).

Contrast-enhanced chest CT scan is recommended to exclude the possibility of lung cancer in patients with hemoptysis and normal chest radiographs, if the patient has two risk factors for malignancy (> 40 years old and $>30$ pack-year smoking history). In adult patients with hemoptysis, the incidence of malignancy was reported as $10-35 \%(2,3)$. In a report on the long-term outcome and incidence of lung cancer in patients with hemoptysis of unknown origin, unresectable lung cancer developed in $6 \%$ of patients within 3 years after the first presentation; all patients were smokers and $>40$ years old (11). In another retrospective study of patients with hemoptysis and normal radiography, $9.6 \%$ of patients were diagnosed with lung cancer; all patients were current or ex-smokers (12).

The accurate assessment of the cause is more important than prompt treatment in patients with moderate hemoptysis (> $30 \mathrm{~mL} / 24$ hours) or recurrent hemoptysis. Previous reports indicate that the most common cause of hemoptysis in Korea was bronchiectasis, followed by active tuberculosis, and tuberculosis sequelae (5). Possible remaining causes were pneumonia, aspergilloma, lung cancer, others, or unknown (5). CT is more useful than bronchoscopy, because it is noninvasive and accurately assesses the cause and site of hemoptysis; in addition, it is also possible to diagnose bronchiectasis, tuberculosis and lung cancer with non-contrast-enhanced CT. However, contrast-enhanced $\mathrm{CT}$ is recommended to accurately assess the bleeding site, because non-bronchial collateral arteries could be the source of bleeding in tuberculosis patients despite the bronchial artery being the common source of bleeding (13-15). Inoperable massive hemoptysis was considered a major indication of bronchial artery embolization; however, moderate hemoptysis or mild but chronic and worsening hemoptysis is also considered an indication of bronchial artery embolization (14). Contrastenhanced CT can guide bronchial artery embolization and reduce procedure time, because it adequately depicts the imaging anatomy of the bronchial artery and non-bronchial collateral arteries (intercostal artery, subclavian artery, axillary artery, and inferior phrenic artery), pulmonary artery and pulmonary vein (16).

A contrast-enhanced CT scan is recommended for patients with massive hemoptysis (> $400 \mathrm{~mL} / 24$ hours) who preserve cardiopulmonary function. Massive hemoptysis can be treated by bronchial artery embolization or surgery; in addition, CT prior to these treatments can be helpful to detect the causative vessel $(7,17)$.

\section{Consideration for Recommendation}

Benefit and Harm

Performing chest radiography as a screening test in patients with hemoptysis is useful in terms of low radiation exposure, lateralization of bleeding site, and as a screening test for lung disease.

Regardless of the amount of hemoptysis, chest CT is recommended in patients who have two risk factors for malignancy ( $>40$ years old and $>30$ pack-year smoking history). Chest CT has the benefit to detect hidden lung cancer that cannot be detected on chest radiography; however, caution is advised due to radiation exposure.

CT is very useful for the simultaneous detection of the bleeding site and cause of bleeding in patients with moderate hemoptysis (>30 mL/24 hours) or recurrent hemoptysis. In Korea, hemoptysis is commonly associated with inflammatory diseases that include active tuberculosis and tuberculosis sequelae. In these cases, chest radiography has several limitations in the evaluation of the bleeding site. CT is therefore very useful for the exact evaluation of

Table 4. Korean Relative Radiation Level

\begin{tabular}{lcl}
\hline & RRL (mSv) & \\
\hline 0 & 0 & Example \\
& $<1$ & Chest radiography (PA view), mammography \\
& $1-5$ & IVU, UGIS, low-dose chest CT, brain CT, brain CTA \\
& $>5-10$ & Routine chest CT, abdominal CT, coronary CT
\end{tabular}

$\mathrm{CT}=$ computed (computer) tomography, CTA = computed tomography angiography, IVU = intravenous urography, MRI = magnetic resonance imaging, RRL = relative radiation level, PA view = posteroanterior view, UGIS = upper gastrointestinal series. Adapted from Choi et al. Korean J Radiol 2017;18:208-216 (2). 
bleeding size and causative disease.

Bronchial artery embolization is considered a treatment option in patients with massive hemoptysis, moderate hemoptysis, or recurrent hemoptysis. CT performed before embolization shows a detailed anatomy of both the bronchial artery and pulmonary artery, helps guide the procedure, and can reduce the procedure time. CT before embolization has significant benefits that outweigh radiation hazards.

Contrast-enhanced CT could have hazards related to the iodine contrast media. We should follow the consultation guide for contrast media that indicates the benefits of contrast media versus the harm from iodine before choosing to use contrast media.

\section{Radiation Dose}

Relative radiation level of chest radiography is less than $1 \mathrm{mSv}$ and that of chest CT is 5-10 mSv (Table 4).

\section{Supplementary Materials}

The online-only Data Supplement is available with this article at https://doi.org/10.3348/kjr.2018.19.5.866.

\section{REFERENCES}

1. ACR Appropriateness Criteria ${ }^{\circledR}$. Hemoptysis. American College of Radiology Web site. https://acsearch.acr.org/docs/69449/ Narrative/. Published August, 2010. Accessed January 31, 2017

2. Choi SJ, Jeong WK, Jo AJ, Choi JA, Kim MJ, Lee M, et al. Methodology for developing evidence-based clinical imaging guidelines: joint recommendations by Korean Society of Radiology and National Evidence-Based Healthcare Collaborating Agency. Korean J Radiol 2017;18:208-216

3. Tsoumakidou M, Chrysofakis G, Tsiligianni I, Maltezakis G, Siafakas NM, Tzanakis N. A prospective analysis of 184 hemoptysis cases: diagnostic impact of chest X-ray, computed tomography, bronchoscopy. Respiration 2006;73:808-814

4. Fidan A, Ozdoğan S, Oruç 0, Salepçi B, Ocal Z, Cağlayan B. Hemoptysis: a retrospective analysis of 108 cases. Respir Med 2002; 96:677-680

5. Bruzzi JF, Rémy-Jardin M, Delhaye D, Teisseire A, Khalil C,
Rémy J. Multi-detector row CT of hemoptysis. Radiographics 2006;26:3-22

6. Lee SJ, Rho JY, Yoo SM, Kim MD, Lee JH, Kim EK, et al. Usefulness of multi-detector computed tomography before bronchoscopy and/or bronchial arterial embolization for hemoptysis. Tuberc Respir Dis 2010;68:80-86

7. Revel MP, Fournier LS, Hennebicque AS, Cuenod CA, Meyer $G$, Reynaud P, et al. Can CT replace bronchoscopy in the detection of the site and cause of bleeding in patients with large or massive hemoptysis? AJR Am J Roentgenol 2002;179:1217-1224

8. Delage A, Tillie-Leblond I, Cavestri B, Wallaert B, Marquette $\mathrm{CH}$. Cryptogenic hemoptysis in chronic obstructive pulmonary disease: characteristics and outcome. Respiration 2010;80:387-392

9. Menchini L, Remy-Jardin M, Faivre JB, Copin MC, Ramon $P$, Matran R, et al. Cryptogenic haemoptysis in smokers: angiography and results of embolisation in 35 patients. Eur Respir J 2009;34:1031-1039

10. Poe RH, Israel RH, Marin MG, Ortiz CR, Dale RC, Wahl GW, et al. Utility of fiberoptic bronchoscopy in patients with hemoptysis and a nonlocalizing chest roentgenogram. Chest 1988;93:70-75

11. Herth F, Ernst A, Becker HD. Long-term outcome and lung cancer incidence in patients with hemoptysis of unknown origin. Chest 2001;120:1592-1594

12. Thirumaran M, Sundar R, Sutcliffe IM, Currie DC. Is investigation of patients with haemoptysis and normal chest radiograph justified? Thorax 2009;64:854-856

13. McGuinness G, Beacher JR, Harkin TJ, Garay SM, Rom WN, Naidich DP. Hemoptysis: prospective high-resolution CT/ bronchoscopic correlation. Chest 1994;105:1155-1162

14. Kim HB. Bronchial artery embolization. In: Korean Society of Interventional Radiology, eds. Interventional radiology, 2nd ed. Seoul: Ilchokak, 2014:321-325

15. Millar AB, Boothroyd AE, Edwards D, Hetzel MR. The role of computed tomography (CT) in the investigation of unexplained haemoptysis. Respir Med 1992;86:39-44

16. Khalil A, Fartoukh M, Parrot A, Bazelly B, Marsault C, Carette MF. Impact of MDCT angiography on the management of patients with hemoptysis. AJR Am J Roentgenol 2010;195:772-778

17. Hsiao EI, Kirsch CM, Kagawa FT, Wehner JH, Jensen WA, Baxter RB. Utility of fiberoptic bronchoscopy before bronchial artery embolization for massive hemoptysis. AJR Am J Roentgenol 2001;177:861-867 